\title{
Multiple fish predators: effects of identity, density, and nutrients on lower trophic levels
}

\author{
Katrin Reiss ${ }^{1,2, *}$, Micah B. Herriot ${ }^{1}$, Britas Klemens Eriksson ${ }^{1}$ \\ ${ }^{1}$ Department of Marine Benthic Ecology and Evolution, Centre of Ecological and Evolutionary Studies, \\ University of Groningen, PO Box 11103, 9700 CC Groningen, The Netherlands \\ ${ }^{2}$ Faculty of Biosciences and Aquaculture, University of Nordland, Postboks 1490, 8049 Bodø, Norway
}

\begin{abstract}
The ongoing loss of predators is changing the composition of food webs, with largely unknown consequences. In particular, the effects of multiple fish predators on food webs are difficult to predict due to the prevalence of omnivory and intraguild predation. At the same time, many ecosystems experience high nutrient loads that fuel food webs from the bottom up. To test the combined effects of both multiple predators and nutrient enrichment on food web composition, we created monocultures of perch, roach, and stickleback as well as mixed assemblages of all 3 species at 3 different density levels using an additive design, and induced nutrient enrichment in half of the cages. The biomass of invertebrate herbivores and algae was measured. Stomach analyses of predators were used to detect prey switching. Herbivore biomass depended mainly on predator identity, while top-down effects on algae were mediated by predator density and nutrient enrichment. Specifically, perch strongly reduced amphipods and isopods, and roach mainly reduced gastropods but also isopods, while stickleback had weak overall effects on herbivores. These species-specific effects were attenuated in the mixed fish assemblages, probably due to prey switching. Algal growth strongly increased under high fish density and nutrient enrichment, but was not affected by predatorinduced changes in the herbivore composition. This study shows that identity effects from predators in isolation are attenuated in multiple predator assemblages, probably due to increasing interference among the predators. Algal biomass was enhanced by nutrient enrichment and high predator density, which affected algae probably through non-lethal effects, such as reduced activity of the herbivores.
\end{abstract}

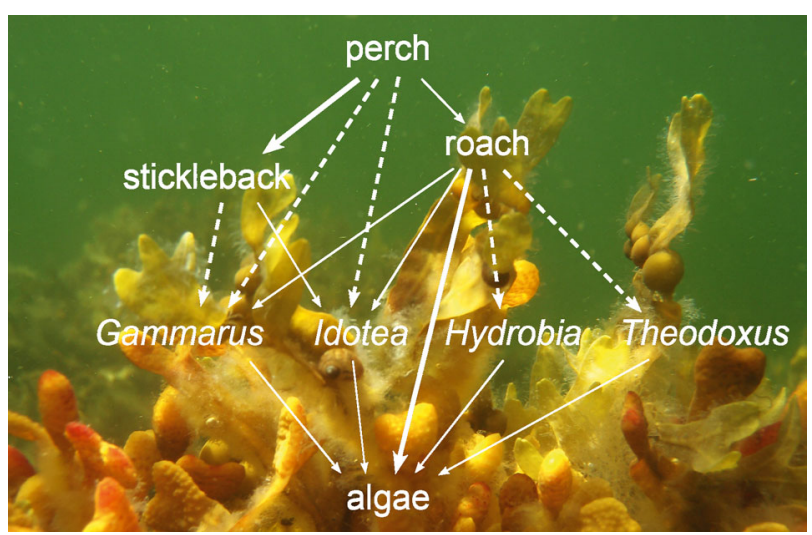

Diagram of food-web interactions (foreground) among fishes, herbivores and algae in the study system (background: brown algae and associated epiphytes and epifauna).

Photo: K. Reiss

KEY WORDS: Diversity - Grazers - Top down · Bottom up - Trait-mediated indirect interactions · Trophic cascade

Resale or republication not permitted without written consent of the publisher

\section{INTRODUCTION}

Ecosystems around the world are presently experiencing the most rapid and dramatic changes since the beginning of market globalization (Lotze et al. 2006). Extinction rates of well-known taxonomic groups are 100 to 1000 times their pre-human levels 
(Pimm et al. 1995). In particular, coastal marine systems, as focal points for human settlement and resource use (Lotze et al. 2006), are altered by species loss and gain (Mack et al. 2000, Worm et al. 2006). The concomitant changes in species diversity and consequences for ecosystem functioning have raised ongoing debates (e.g. Cardinale et al. 2012, Naeem et al. 2012). Adding or removing species changes both the species richness and the species composition of a community. Studies that compared the importance of richness and composition effects in diversity experiments, often found the latter, also called idiosyncratic effects, to be of larger magnitude (Stachowicz et al. 2007). Thus, the identity of the species that is lost or gained seems to play a key role in predicting the consequences for the ecosystem.

From a food web perspective, the effects of multiple predators on prey removal are often non-additive through either 'risk enhancement' (e.g. diet complementarity or facilitation among predators) or 'risk reduction' (e.g. intraguild predation or omnivory) (see Sih et al. 1998 for a summary). Thus, interactions among predator species determine the food web effects of multiple predators, where intraspecific interference may be as strong as interspecific interference (Sih et al. 1998, Griffen 2006). Accordingly, experimental studies have shown that emergent multiple predator effects strongly depend on predator densities (e.g. Vance-Chalcraft et al. 2004, Griffen \& Williamson 2008, Griffin et al. 2008). Hence, due to emergent interference among predators, both, predator identities and their corresponding densities have to be considered when testing the food web effects of multiple predators.

Changes in the predator community may be transmitted via intermediate species (mesopredators and/ or herbivores) to indirectly affect primary producers through a trophic cascade (Pace et al. 1999). Such predator effects on producers may be transferred through numerical changes in the intermediate level that are dependent on predator density (densitymediated indirect interactions, DMIIs) or through induced phenotypic responses in the intermediate level without numerical changes (trait-mediated indirect interactions, TMIIs) (Werner \& Peacor 2003). Thus, herbivore traits, especially edibility (predator resistance), grazing efficiency, and feeding guild, are important mediators of multiple predator effects on lower trophic levels (Stachowicz et al. 2007). The resulting biomass and species composition of primary producers is ultimately determined by the functional composition of the herbivores combined with nutrient availability (Råberg \& Kautsky 2007).
Accordingly, it has been shown that the loss of dominant fish predators in the coastal zone of the Baltic Sea has reduced grazing rates on algae by shifting the functional composition of the herbivore community (Eriksson et al. 2009, Sieben et al. 2011). Furthermore, cascading effects on the algae interacted with nutrient enrichment (Sieben et al. 2011), highlighting the importance of nutrient availability for cascading trophic effects.

These studies recorded changes in the food web in either the absence or presence of top predators. However, changes within the fish community, specifically changing predator composition and densities, were not considered. The Baltic Sea is a semienclosed brackish water system and is subjected to both high fishing pressure and elevated nutrient loads, which have induced both changes in the fish community and large-scale eutrophication (e.g. Eriksson et al. 2011, Gustafsson et al. 2012). Therefore, the food web effects of changing fish communities, especially combined with elevated nutrient levels, is of immediate relevance for management strategies in the Baltic Sea region.

In this study, we investigated food web effects of multiple fish predators together with nutrient enrichment on the herbivore and algal community in a field experiment. We compared the combined effects of 3 predators in a mixed assemblage with their isolated effects in monoculture, and we examined the roles of predator identity, predator density, and nutrient availability for their combined effects in multiple predator assemblages. We used 3 common fish species of the Baltic coastal zone, Perca fluviatilis L. (European perch), Rutilus rutilus (L.) (roach) and Gasterosteus aculeatus L. (3-spined stickleback) (Ådjers et al. 2006), which have partly overlapping food preferences (Fig. 1). The predatory perch has strongly declined in abundance in some parts of the Baltic Sea since the early 1990s, which is mainly attributed to recruitment failures (Nilsson et al. 2004, Ljunggren et al. 2010), and may be linked to shifts in offshore food webs (Ljunggren et al. 2010). At the same time, increasing abundances of the smaller mesopredator stickleback have been observed (Ljunggren et al. 2010, Eriksson et al. 2011). Comparable changes in abundance of the omnivorous roach have not been reported so far. In the Baltic coastal zone, the benthic herbivores that live in association with the abundant habitat-forming brown alga Fucus vesiculosus L. are dominated by amphipods, isopods and gastropods. Predators were assembled following an additive design. This design allowed interspecific interference among the predators to be detected, 


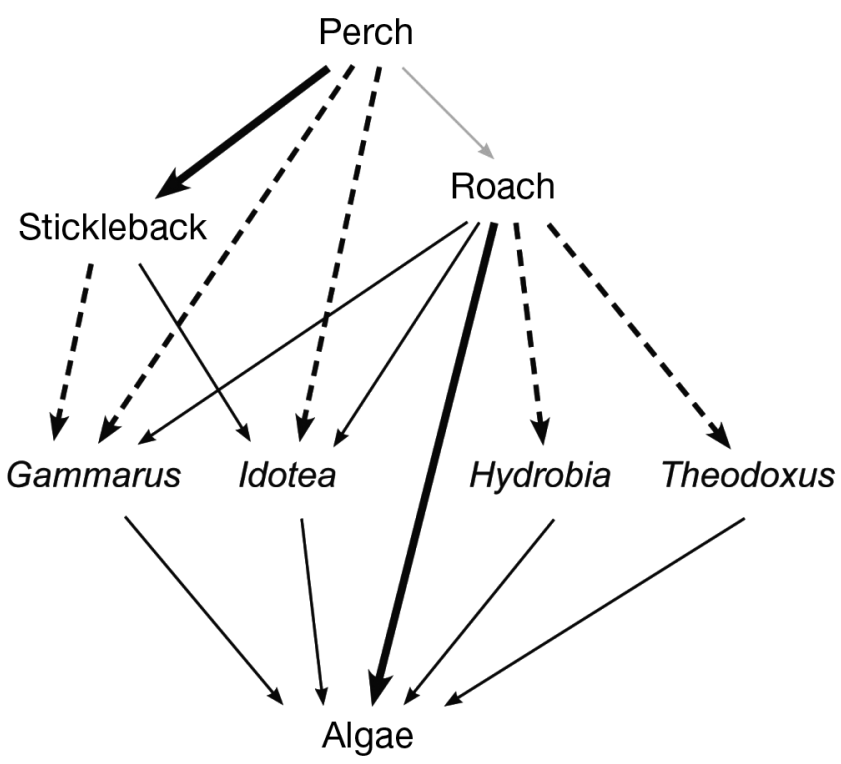

Fig. 1. Food web interactions based on the results of the present study. Changes in food preferences from the fish monocultures compared with the diverse fish assemblages are shown. Consumption either increased (thick solid line, mixed assemblage $>$ monoculture), decreased (dashed line, monoculture $>$ mixed assemblage) or remained the same (thin solid line). Note: the grey arrow from perch to roach indicates nonconsumptive interference as observed during the experiment

since their respective densities were the same in monocultures and mixed assemblages. However, total density increases in mixed assemblages and is therefore confounded with species richness (Griffen 2006). Therefore, we used monocultures and mixed assemblages at 3 density levels to estimate the effect of density on interference among conspecific predators (in the monocultures) and multiple predators (in the mixed assemblages). Because of partly shared resources and differing trophic positions of the 3 fish species (Fig. 1) - top predator (perch), mesopredator (stickleback) and omnivore (roach) - we expected interference effects in the mixed assemblages to result in non-additive effects on prey.

We hypothesized that (1) predator identity would determine the herbivore composition in monocultures (we had indications that perch and stickleback mainly predate on amphipods and isopods, and roach on gastropods; Sieben et al. 2011, K. Reiss pers. obs.); (2) interspecific interference among predators would occur in the mixed assemblages and that the resulting non-additive effects on herbivores would be caused by prey switching; (3) increasing predator density would increase total prey removal in monocultures as well as in mixed assemblages (although per capita effects may decrease); (4) nutrient enrichment would enhance predator effects on herbivores; and, accordingly, (5) algal biomass would increase with high predator density and nutrient enrichment.

\section{MATERIALS AND METHODS}

\section{Study system and organisms}

The study site was located at the inner archipelago of the Askö area $\left(58^{\circ} 48^{\prime} \mathrm{N}, 17^{\circ} 40^{\prime} \mathrm{E}\right)$, western Baltic Proper. The site is sheltered and non-tidal; fluctuations in the water levels are mainly wind (or air pressure) driven, and summer water temperatures and salinity range from 17 to $20^{\circ} \mathrm{C}$ and from 6.3 to 6.5 , respectively (http://www2.ecology.su.se/dbhfj/b1start.htm). The bottom substrate is mainly sand and gravel, scattered with rocks and boulders. The dominating brown alga Fucus vesiculosus L. (hereafter Fucus) is an important habitat provider for diverse invertebrate species and epiphytic algae. Abundant benthic producers, other than Fucus, are mainly ephemeral green (e.g. Cladophora glomerata (L.) Kützing, Ulva spp.) and brown (e.g. Pilayella littoralis (L.) Kjellman) algae, as well as diatoms (e.g. Melosira spp.). The fish community includes both marine and freshwater species, but the latter dominate in the coastal zone. The fish species used in this study were Perca fluviatilis L. (European perch, hereafter perch), Rutilus rutilus (L.) (roach) and Gasterosteus aculeatus L. (3-spined stickleback, hereafter stickleback), which are among the most abundant fish species in the study area (K. Reiss pers. obs.). Perch is a very common fish, often occurring among aquatic vegetation (HELCOM 2006). It is strictly carnivorous and undergoes substantial diet shifts during its ontogeny, from feeding on zooplankton to macroinvertebrates to fish (Persson 1987, Lappalainen et al. 2001, Kahl \& Radke 2006 and references therein). Large perch feed on, for example, juvenile stages of roach and perch, stickleback (K. Reiss pers. obs.), and crustaceans (Eklöv \& Persson 1995, Lappalainen et al. 2001). Roach, as a true omnivore, prefers gastropods and other molluscs, but also consumes other zoobenthos, zooplankton, detritus, phytoplankton, and macrophytes (Persson 1987, Lappalainen et al. 2001, Kahl \& Radke 2006). In contrast to perch, roach feed on prey of a similar size over their entire life period (Eklöv \& Persson 1995). Stickleback is the dominant mesopredator in the system and prefers zooplankton over benthic prey, but as the availability of zooplankton decreases, zoobenthos becomes more important (Ibrahim \& Huntingford 1989). In the study area, stickleback mainly feed on gam- 
marid amphipods, copepods and the larvae of Chironomidae (K. Reiss pers. obs.). The invertebrate herbivore community associated with Fucus is dominated by amphipods (Gammarus spp., hereafter Gammarus), isopods (Idotea balthica (Pallas), Idotea chelipes (Pallas), hereafter together as Idotea) and gastropods (Theodoxus fluviatilis (L.), Hydrobia ventrosa (Montagu) and Hydrobia ulvae (Pennant), hereafter Theodoxus and Hydrobia) that represent 2 different feeding guilds. Amphipods and isopods are shredders and considered to be selective omnivores, feeding on filamentous macroalgae and larger plant material, as well as fine detritus, other invertebrates and fish eggs (Salemaa 1987, MacNeil et al. 1997, Sommer 1997, Orav-Kotta \& Kotta 2003). Gastropods scrape off mainly diatoms and other microalgae from surfaces, but also feed on macroalgal recruits and young thalli of Cladophora glomerata (Neumann 1961, Korpinen et al. 2008).

\section{Experimental design}

We tested the effects of fish assemblages varying in composition and density combined with nutrient enrichment on the structure of the herbivore community, as well as subsequent effects on algal biomass. We created monocultures of 3 fish species (stickleback, roach, perch) and mixed assemblages of all 3 species in field cages (fish $=4$ levels). All fish treatments were conducted at 3 different density levels (density = 3 levels). Additionally, nutrient enrichment was simulated in half of the cages (nutrients $=2 \mathrm{lev}-$ els). In total, 24 cages were used. That means that 1 cage represented 1 experimental plot with a unique combination of the 3 experimental factors. In each cage, we placed 3 sampling units for herbivores and 2 units for algae. Thus, replicates were not independent in a full combination of all 3 factors, but rather represented the conditions in each cage. Therefore, we omitted 3-way interactions in the analysis and interpreted interaction effects with great caution (see 'Statistical analysis'). The complex design and a low sample size resulted in low statistical power, which is considered in the 'Discussion'. The experiment was performed without predator-free controls, which could have provided 'natural' (caged) densities of herbivores and algae. Thus, we were not able to measure absolute predator effects on herbivores from our data, but we measured the relative differences of predation effects from the 3 fish species and were able to compare those with their combined effect in the multiple fish assemblages.
The fish treatment was based on a simple additive design, which means that predator density increased in the mixed assemblages. This implies that the density of each species in a mixed assemblage is the same as in its monoculture, and that total density is greater in the mixed assemblage. With this design it is possible to test whether (non-additive) interspecific effects of multiple predators occur and whether their sum effect is positive (through risk enhancement) or negative (through risk reduction) (Snaydon 1991). However, the effects of having multiple predators are confounded with increasing predator density in additive designs (Byrnes \& Stachowicz 2009). Furthermore, with an additive design alone one cannot estimate the relevance of interspecific interference compared with intraspecific interference among predators. Substitutive designs have comparable drawbacks, and therefore a combination of both designs may be ideal (e.g. Griffen 2006, Byrnes \& Stachowicz 2009), but this was not feasible in our study. However, to estimate the effects of predator density, we employed all fish treatments at 3 density levels. With this, we were able to estimate the interference among conspecifics on prey consumption (in the monocultures), as well as interspecific effects with increasing total predator density (in the mixed assemblages).

\section{Experimental procedure}

The cages $(120 \times 55 \times 100 \mathrm{~cm}$, length $\times$ width $\times$ height) were steel-framed and covered with a nylon fishing net (mesh size, $6 \mathrm{~mm}$ ). The treatments were randomly distributed in shallow water (1.2 m deep) in a sheltered bay. Nutrient enrichment was simulated in half of the cages (2 levels) by attaching 4 net bags filled with slow-release agricultural fertilizer (Plantacote Depot 6M; $120 \mathrm{~g}$ fertilizer in each bag) to each cage frame. The same amount of fertilizer applied to identical cages in the same bay in July 2007 resulted in a $\sim 70 \%$ increase of total phosphorus (mean \pm SE: from $2.95 \pm 0.2$ to $4.99 \pm 0.75 \mu \mathrm{g} \mathrm{l}^{-1}$ ) and $\sim 105 \%$ increase of total nitrogen (from $3.64 \pm 0.47$ to $7.49 \pm 1.52 \mu \mathrm{g} \mathrm{l}^{-1}$ ) compared with the ambient nutrient level (Sieben et al. 2011). Nutrient concentrations were measured in the water column $\sim 30 \mathrm{~cm}$ from the fertilizer bags. The experiment ran for $3 \mathrm{wk}$ from 12 July to 3 August 2008.

Fish numbers in the low-, medium-, and high-density treatments were 2,4 , and 6 individuals of perch and roach, and 15, 30, and 45 individuals of stickleback, respectively. That means, for example, that a high-density mixed assemblage contained 6 perch, 
6 roach and 45 sticklebacks. Thus, predator densities in high-density mixed assemblages were probably unnaturally high. However, perch and roach are solitary species, which may imply that enclosing several individuals of such species always delivers densities that are too high, while stickleback is a schooling fish and school sizes of about 20 individuals have been observed in the study area.

Sticklebacks and roach were caught at the field station using drop nets and traps, respectively. Perch were caught with gill nets. All fishes were kept in tanks for 3 to $5 \mathrm{~d}$ prior to the experiment and only individuals that had a specific length, seemed healthy, and in good condition were selected for the experiment. Perch had an average length and weight of $14.8 \pm 0.3 \mathrm{~cm}$ and $35.9 \pm 2.9 \mathrm{~g}(\mathrm{~N}=47)$, respectively, a size which was assumed as sufficient for perch to be piscivorous (feeding on stickleback of the size used in this study in the study area, K. Reiss unpubl. data). Roach had an average length and weight of $15.2 \pm$ $0.3 \mathrm{~cm}$ and $41.6 \pm 3.3 \mathrm{~g}(\mathrm{~N}=47)$, respectively. Stickleback had an average length and weight of $1.2 \pm$ $0.3 \mathrm{~cm}$ and $1.8 \pm 0.5 \mathrm{~g}(\mathrm{~N}=360)$, respectively, and had a different total biomass to perch and roach due to low individual body weight of stickleback. Therefore, we chose numbers appropriate for forming schools. The resulting biomass ratio between perch and roach was 1:1, and between perch and roach, and stickleback was approximately 1:3, in both monocultures and mixed assemblages. Fish condition was checked daily by snorkelling around the cages. Mortality during the experiment was found for sticklebacks only, and was probably due to consumption (by perch in the mixed assemblages). Missing sticklebacks and other fishes that appeared to be in poor condition were replaced as fast as possible.

Specimens of Fucus were used as habitat and sampling unit for the herbivore communities. Fucus was collected close to the study site, cleaned of invertebrates and epiphytes, tied in bundles of $\sim 200 \mathrm{~g}$ wet weight, and kept in outdoor tanks for a few days prior to the start of the experiment. Three Fucus bundles were used in each cage. At the end of the experiment, the invertebrates were collected by pulling a net bag (mesh size, $1 \mathrm{~mm}$ ) over the Fucus, enclosing all the associated fauna under water. Algal growth was examined on 2 ceramic tiles glued on bricks in each cage. The bricks were placed on the bottom of the cages at a minimum distance of $20 \mathrm{~cm}$ from the Fucus bundles and the netting of the cage.

At the end of the experiment, fish total length and biomass were measured, and the stomachs were removed and frozen $\left(-18^{\circ} \mathrm{C}\right)$ for later analyses. Herbi- vores and algae were also frozen $\left(-18^{\circ} \mathrm{C}\right)$. In the laboratory, herbivores were rinsed off the Fucus, sorted into species, counted, and dry weighed (after drying at $60^{\circ} \mathrm{C}$ for a minimum of $48 \mathrm{~h}$ ). Dry biomass was converted into ash-free dry weight and shell-free dry weight with the use of conversion factors (Lappalainen \& Kangas 1975). In the data analyses, the dominant species of the herbivore groups amphipods (Gammarus spp.), isopods (Idotea spp.) and gastropods (Hydrobia spp. and Theodoxus fluviatilis) were used.

Algae were scraped off from the surface of the tiles, sorted to the lowest possible taxonomic level, and dry weighed (after drying at $80^{\circ} \mathrm{C}$ for a minimum of $48 \mathrm{~h}$ ).

The herbivore samples taken inside the cages were used as the main response (for statistical analyses), because these (remaining) herbivores could transmit predation effects further to the producer level. In addition to the measures of herbivore biomass inside the cages, we used stomach analyses to estimate the extent to which herbivores and other sources contributed to the predators' diet and to detect whether prey switching occurred.

\section{Statistical analysis}

All analyses were conducted using $\mathrm{R}$ version 2.15. (R Development Core Team 2012). In each cage, 3 herbivore and 2 algae samples were taken. Thus, herbivore biomass and algal biomass were the response variables. The treatments 'fish' (4 levels: perch, roach, stickleback, all), 'density' (3 levels: low, medium, high), and 'nutrients' (2 levels: ambient, enriched) were all included as fixed factors. Cage number (1 to 24) was included as a random factor.

First, we tested the effect of 'cage' on the response variables. We compared models that included the random factor using the lme-function (linear mixed-effects [LME], from the nlme-package, Pinheiro et al. 2013) with models that included only fixed factors using the gls-function (generalized least squares [GLS], also from the nlme-package) for each of the response variables, and chose between the 2 depending on the goodness of model fit (via Akaike's information criterion). GLS models are able to handle heterogeneity of variances by defining specific variance structures for the models (Zuur et al. 2009). Therefore, we could omit data transformations for GLS models. For the GLS models, we chose the optimal variance structure (varIdent) depending on graphical plot validation (standardized residuals vs. fitted values). Similarly, the optimal random part for the LME models was chosen. For the response variables 'Gammarus biomass', 
'Idotea biomass', and 'Theodoxus biomass', GLS models were applied; for 'Hydrobia biomass' and 'Algal biomass', LME models were applied. Thus, 'cage' affected the responses of Hydrobia and algae, but not Gammarus, Idotea, and Theodoxus. Therefore, results on Hydrobia and algae must be considered carefully.

Starting from the full model (with all 2-way interactions), model simplification was performed to find the optimal fixed components of all models. Thus, after defining the full model for each response variable, stepwise model selection was used to select the minimum adequate model (see Zuur et al. 2009 for the entire statistical procedure). When treatment effects were significant, pairwise $t$-tests (from the stats package) were applied, including Bonferroni corrections (same package), to correct for multiple comparisons. Comparisons of the 'strongest' (i.e. producing the lowest grazer biomass for each grazer group) monocultures against the mixed assemblages tested whether interspecific interactions occurred in the multiple predator treatment.

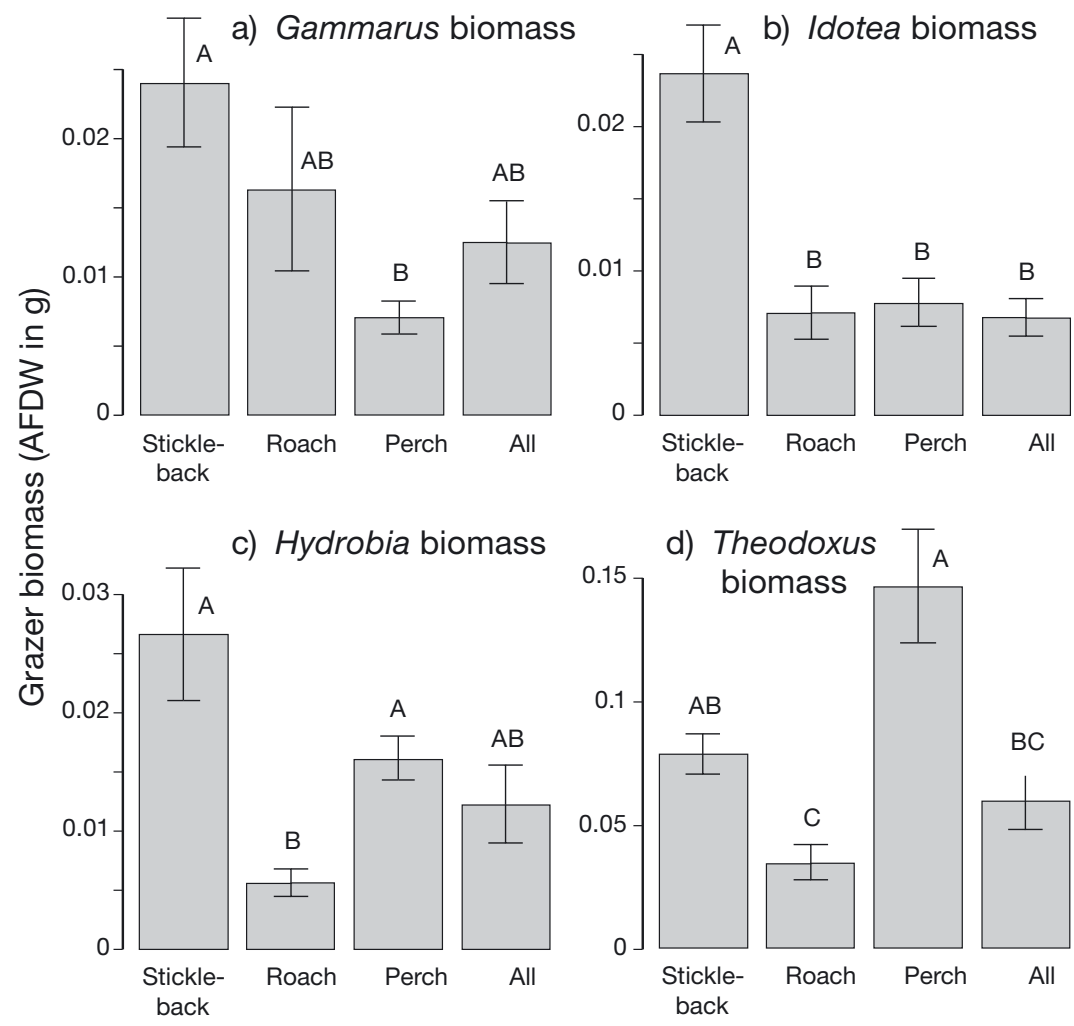

Fig. 2. Biomass (ash free dry weight, AFDW in g) of (a) amphipods (Gammarus), (b) isopods (Idotea), and the gastropods (c) Hydrobia and (d) Theodoxus in the different fish enclosures, averaged over fish density and nutrient treatment. 'Stickleback', 'perch' and 'roach' denote the respective species in monoculture; 'all' denotes the mixed assemblage of all fish species. Different letters indicate significant differences $(p<0.05)$ from post-hoc tests. Values are mean $\pm \mathrm{SE}$
Specific planned comparisons (from the contrast package; Kuhn et al. 2011) with Bonferroni corrections were used to detect sources of variance differences from significant interactions.

\section{RESULTS}

\section{Experimental setting}

Over the course of the experiment, 2 perch and 6 roach (each out of 48) were replaced when they appeared to be in poor condition. Additionally, 30 stickleback (out of 360) were replaced, either due to bad condition or because they were consumed. Herbivore biomass on the Fucus was dominated by gastropods (62\% of the mean invertebrate biomass per Fucus), amphipods (13\%) and isopods (9\%). Other abundant non-grazing invertebrates were chironomid larvae $(11 \%)$, and bivalves, nemerteans, and polychaetes (together $5 \%$ ). Algal biomass was strongly dominated by one species, Cladophora glomerata (L.) Kützing (87\% of the mean biomass). Pylaiella littoralis (L.) Kjellman and Ulva spp. made up 9 and $3 \%$ of the total algal biomass, respectively.

\section{Effects of predator identity in mono- cultures (hypothesis 1)}

Perch mainly reduced amphipod and isopod biomass. In perch monocultures, Gammarus biomass decreased by $71 \%$ compared with stickleback assemblages, which showed the highest Gammarus biomass (Fig. 2a, Table 1). Likewise, biomass of the isopod Idotea was $67 \%$ lower in perch monocultures compared with the stickleback monocultures (Fig. 2b, Table 1). Roach monocultures, like perch, also reduced Idotea by $70 \%$ compared with stickleback. In contrast to perch, roach had no significant impact on Gammarus biomass, but strongly reduced gastropod biomass. Both Hydrobia and Theodoxus biomass were significantly lower in the roach monocultures compared with the other monocultures (post-hoc tests: stickleback-roach $\mathrm{p}=$ 0.019 and perch-roach $p=0.0004$ for Hydrobia, stickleback-roach $\mathrm{p}=$ 
Table 1. Statistical analysis of variances of invertebrate biomass and algal biomass from generalized least squares or $\left({ }^{\mathrm{a}}\right)$ linear mixed effects models after model selection.

$$
{ }^{*} \mathrm{p}<0.05,{ }^{* *} \mathrm{p}<0.01,{ }^{* * *} \mathrm{p}<0.001
$$

\begin{tabular}{|clrrc|}
\hline $\begin{array}{c}\text { Response } \\
\text { variable }\end{array}$ & Variable & df & F-value & p-value \\
\hline Gammarus & Fish & 3 & 5.37 & $0.002^{* *}$ \\
biomass & Nutrients & 1 & 4.05 & $0.048^{*}$ \\
Idotea & Fish & 3 & 12.88 & $<0.0001^{* * *}$ \\
biomass & Density & 2 & 3.88 & $0.026^{*}$ \\
& Fish: Density & 6 & 3.39 & $0.006^{* *}$ \\
Hydrobia $_{\text {biomass }}{ }^{\text {a }}$ & Fish & 3 & 7.26 & $0.011^{*}$ \\
& Nutrients & 1 & 4.27 & 0.073 \\
& Density & 2 & 0.87 & 0.454 \\
Theodoxus & Fish: Nutrients & 3 & 2.89 & 0.102 \\
biomass & Fish: Density & 6 & 2.20 & 0.149 \\
& Nutrients & 3 & 59.09 & $<0.0001^{* * *}$ \\
& Density & 1 & 0.36 & 0.552 \\
Algal & Fish: Nutrients & 3 & 3.11 & 0.053 \\
biomass & Fish: Density & 6 & 8.80 & $<0.006^{* *}$ \\
& Fish & 3 & 0.80 & 0.521 \\
& Nutrients & 1 & 20.41 & $0.001^{* * *}$ \\
& Density & 2 & 11.69 & $0.002^{* *}$ \\
& Fish: Density & 6 & 2.03 & 0.146 \\
\hline
\end{tabular}

0.009 and perch-roach $\mathrm{p}=0.002$ for Theodoxus, Fig. 2c,d).

Algal biomass, in contrast, was not affected by fish identity in the monocultures.

\section{Effects of multiple predators (hypothesis 2)}

Mixed fish assemblages attenuated the negative effects on 3 of the 4 herbivore groups compared with their strongest predator in monoculture. However, herbivore biomass in the 'strongest monocultures' was not significantly different from the mixed assemblages. Instead, herbivore biomass in the mixed assemblages was intermediate between the 'strongest' and 'weakest' monocultures.

Gammarus biomass in the mixed assemblages was higher than in monocultures of their strongest predator, perch (both compared with stickleback): monocultures of perch and stickleback ( $\mathrm{p}=0.021$ ) were significantly different, but mixed assemblages and stickleback monocultures were not $(\mathrm{p}=$ 0.375). Both gastropods occurred in the mixed fish assemblages in higher biomass than in the monocultures of their strongest predator, roach (each compared with the highest biomass monoculture, Fig. 2c,d). In the mixed fish assemblages, Hydrobia biomass was more than twice as high as in the roach monocultures. Similarly, Theodoxus biomass in the mixed assemblages was $42 \%$ higher than in the roach monocultures. Finally, biomass of Idotea in the mixed assemblages was as low as in monocultures of perch and roach compared with the stickleback monocultures (Fig. 2b, Table 1). Algal biomass in the multiple fish assemblages did not differ from any monoculture.

\section{Effects of predator density (hypotheses 3 and 5)}

Fish density had ambiguous effects on herbivore composition. Increasing fish density, particularly densities of stickleback and roach, increased the biomass of Idotea (contrast on fish: density, $t=3.25$ and $\mathrm{p}=0.008$ for stickleback, $t=2.62$ and $\mathrm{p}=0.044$ for roach). However, overall predation effect of stickleback on Idotea was weak compared with the other fish assemblages. Furthermore, fish density reduced the biomass of Theodoxus but not Hydrobia. Increasing fish density from medium to high reduced Theodoxus biomass ( $\mathrm{p}=0.053$, Table 1 ) across all fish assemblages. Particularly in the mixed assemblages, high fish density significantly decreased Theodoxus biomass (contrast on fish: density (medium to high), $t=3.04, \mathrm{p}=0.014)$.

Algal growth increased 6-fold with high fish density (low density [mean $\pm \mathrm{SE}$ ]: $0.003 \pm 0.0008 \mathrm{~g} \mathrm{dm}^{-2}$; medium density: $0.003 \pm 0.001 \mathrm{~g} \mathrm{dm}^{-2}$; high density: $0.0175 \pm 0.0046 \mathrm{~g} \mathrm{dm}^{-2}$ ), which was clearly apparent in all fish treatments except for the monocultures of the omnivorous roach (Table 2a). However, there was no significant interaction effect of fish composition and density (Table 1).

Table 2. Biomass of ephemeral macroalgae (dry weight in $\mathrm{g} \mathrm{dm}^{-2}$ ) depending on fish density and (a) fish assemblage and (b) nutrient enrichment. 'Stickleback', 'perch' and 'roach' denote the respective species in monoculture; 'all' denotes the mixed assemblage of all fish species. Values are mean $\pm \mathrm{SE}$

\begin{tabular}{|llll|}
\hline \multicolumn{1}{c}{ Low density } & Medium density & High density \\
\hline a) Fish assemblage & & \\
Stickleback & $0.0027 \pm 0.0012$ & $0.0003 \pm 0.0002$ & $0.0198 \pm 0.0113$ \\
Roach & $0.0034 \pm 0.0024$ & $0.0062 \pm 0.0028$ & $0.0057 \pm 0.0019$ \\
Perch & $0.0039 \pm 0.0016$ & $0.0026 \pm 0.0021$ & $0.0143 \pm 0.0083$ \\
All & $0.0018 \pm 0.00113$ & $0.003 \pm 0.0009$ & $0.0301 \pm 0.0109$ \\
b) Nutrient enrichment & & \\
Ambient & $0.0018 \pm 0.001$ & $0.0009 \pm 0.0003$ & $0.0053 \pm 0.0019$ \\
Enriched & $0.0042 \pm 0.0011$ & $0.0052 \pm 0.0016$ & $0.0297 \pm 0.0067$ \\
\hline
\end{tabular}




\section{Effects of nutrient enrichment (hypotheses 4 and 5)}

High nutrient levels significantly decreased Gammarus biomass by $19 \%$ across all fish treatments (ambient $[$ mean $\pm \mathrm{SE}]: 0.0166 \pm 0.0031 \mathrm{~g}$; enriched: $0.0134 \pm 0.003 \mathrm{~g}$; Table 1). In contrast, Theodoxus biomass increased with nutrient enrichment depending on the fish assemblages (fish: nutrients interaction effect, Table 1). Specifically, in the monocultures of stickleback, Theodoxus aggregated in higher biomasses under elevated nutrient levels (contrast on fish: nutrients, $t=2.98, \mathrm{p}=$ 0.017). Similarly, Hydrobia showed a trend towards higher biomass in enriched assemblages ( $p=0.073$, Table 1$)$.

Algal biomass increased 5-fold under nutrient enrichment in all fish assemblages (ambient [mean $\pm \mathrm{SE}$ ]: $0.0027 \pm 0.0008 \mathrm{~g} \mathrm{dm}^{-2}$; enriched: $0.013 \pm 0.0033 \mathrm{~g} \mathrm{dm}^{-2}$; Table 1; see also Table $2 b)$.

\section{Stomach analyses (hypothesis 2)}

Stomach content analyses supported our hypothesis that the reduced predator-specific effects in the mixed fish assemblages would depend on prey switching. Perch in monoculture consumed mainly amphipods and isopods (Table 3), which made up to 49 and $47 \%$ of their stomach content, respectively. In mixed assemblages, the amount of amphipods and isopods in the diet of perch was reduced to 18 and $10 \%$, respectively. Perch instead consumed substantial amounts of unique food items - stickleback and decapods, which added up to 43 and $26 \%$, respectively, of their stomach content in the mixed assemblages. Thus, perch partly switched to feeding on stickleback (intraguild predation) when available. Roach consumed mainly amphipods (45 and $40 \%$ in monocultures and mixed assemblages, respectively), isopods (8 and 6\%), gastropods (4 and $5 \%$ ) and algae (4 and $13 \%$, Table 3 ).

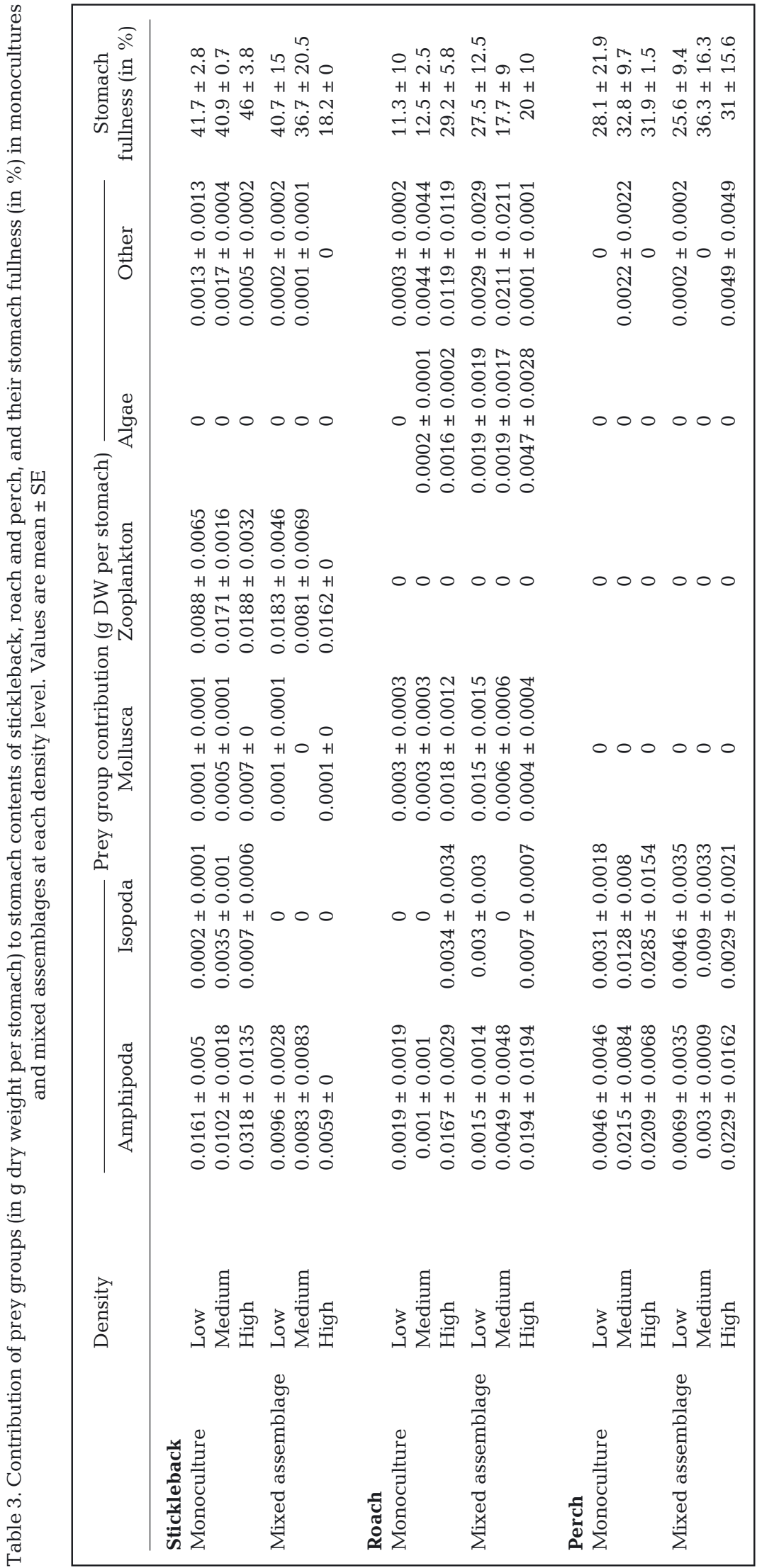


Roach consumed 3 times more algae when kept in high densities and 5 times more in the mixed assemblages, supporting the hypothesis that roach switches prey when competition increases. In addition, the roach stomachs contained large amounts (overall average, $38 \%$ ) of unidentifiable organic material with greenish coloration, indicating algae in a partly digested stage. This unidentifiable organic material was found in particularly large amounts in stomachs of roach from nutrient-enriched assemblages and from mixed assemblages, suggesting that at least parts of this organic material was algae and indicating the ability of roach to consume large amounts of algae.

Stickleback mainly consumed amphipods (45 and $32 \%$ in monocultures and mixed assemblages, respectively) and zooplankton (43 and 54\%, mainly copepods and ostracods, Table 3 ). In the mixed fish assemblages, the biomass of amphipods in stomachs of stickleback decreased together with their stomach fullness (from 47 to $36 \%$, Table 3 ), compared with the monocultures.

\section{DISCUSSION}

We demonstrated that predators had strong identity effects on herbivore composition in monocultures: perch mainly reduced Gammarus and Idotea, and roach mainly reduced Idotea and gastropods, both compared with stickleback monocultures, which had the weakest effects on herbivores (in line with hypothesis 1). Multiple predator assemblages reduced the removal of 3 of the herbivore groups, Gammarus and both gastropods (in line with hypothesis 2), compared with the strongest monocultures. Stomach content analyses supported the hypothesis that predators switched prey when they were kept together in a mixed assemblage. Predator density had ambiguous effects on herbivores (in contrast to hypothesis 3). Idotea biomass increased with high predator density, whereas Theodoxus decreased with high predator density (mainly in the multiple predator assemblages). In contrast, Gammarus and Hydrobia biomass did not respond to increasing fish density, although both were strongly predated by perch and roach, respectively. Furthermore, we hypothesized that nutrient enrichment would enhance predator effects on herbivores. In line with this hypothesis (hypothesis 4), Gammarus biomass was reduced across all fish assemblages when the cages were nutrient enriched. However, in contrast to this hypothesis, Theodoxus biomass increased in enriched assemblages. Primary production was strongly enhanced by both high fish density and nutrient enrichment (in line with hypothesis 5), while predator identity had no effect. The strong indirect effect of high fish density on algal biomass with no associated changes in the herbivore composition suggests that non-lethal interactions (reduced activity of the herbivores) may have mediated top-down effects.

Species-specific predation on herbivores by both perch and roach declined in the mixed fish assemblages (Fig. 1). Predators can reduce interference with other predators by changing the feeding mode and/or foraging habitat (Crowder \& Cooper 1982, Werner et al. 1983). In the present study, perch stomachs from the monocultures almost exclusively contained amphipods and isopods, while in the mixed fish assemblages they fed to a substantial degree on mesopredators (stickleback and shrimp), food items that are probably more profitable in terms of their nutritional and energy content than the herbivores. In contrast, roach switched to a less efficient food source, algae, when kept in mixed assemblages. Stickleback, when kept in mixed assemblages, removed less of its main food item than in monoculture (amphipods), but did not compensate through alternative exploitation and fed generally less (stomach fullness decreased by $11 \%$ ) in the presence of its own predator, perch. This suggests that the strength of identity effects in a species mixture (as observed from the species in isolation) depends on the species' interference with conspecifics as well as heterospecifics. A study similar to ours found higher survival of some predators in a mixed assemblage compared with their monoculture, suggesting that intraspecific interference may be even higher than interspecific interference (Douglass et al. 2008). Within this study, we were not able to compare the strengths of intraspecific versus interspecific effects. However, our results indicate that interspecific interference among the predators reduced removal of the key herbivore groups through prey switching.

Multiple predators increase the likelihood of competition and intraguild predation. Intraguild predation is common, particularly when predators embrace different size classes, and can have strong positive effects on their prey, e.g. in marine benthic communities (Polis et al. 1989, Polis \& Holt 1992 and references therein). Thus, multiple predators can lower the total impact on the prey (Soluk 1993) and reduce the strength of trophic cascading effects $\left(\mathrm{O}^{\prime}\right.$ Gorman et al. 2008, O'Connor \& Bruno 2009). In this experiment, the competitively superior perch consumed stickleback when they were kept together in mixed 
assemblages (intraguild predation). Competitively inferior predators on the other hand may switch to less profitable alternative resources. For example, omnivorous predators (such as roach) may avoid competition by exploiting basal resources. In this experiment, roach stomachs contained more algal food when kept in high densities and mixed assemblages (monoculture: $4 \%$, mixed: $13 \%$ of the stomach content in the high density assemblages). Accordingly, algal biomass did not increase at high densities in the roach monoculture as it did in all other high-density assemblages (Table 3, but statistically not significant). Thus, including an omnivore can have negative effects on the producers by directly removing significant amounts of algae (Bruno \& O'Connor 2005), which may dampen top-down effects. Thus, multiple predator assemblages can reduce the total predation on herbivores due to increasing interference among predators causing positive effects on algae. However, including an omnivore in this assemblage may neutralize the positive effects on algae.

The effects of fish density on herbivores were less pronounced than the effects of fish composition. High predator densities in the mixed assemblages reduced Theodoxus to a lower biomass than in monocultures of roach (their strongest predator), although roach occurred in both treatments in the same numbers. This may suggest that predator facilitation enhanced prey removal. In contrast, Idotea biomass increased with high predator densities in 2 of the monocultures. Thus, isopods were released from predation when predator densities were high. Together, this may suggest that whether multiple predators facilitate or hamper, their combined effect on prey depends on predator density as well as prey identity. Similarly, Douglass et al. (2008) have shown that predator diversity effects on herbivores depend on both predator identities and densities.

However, total predator density had strong positive effects on algal growth. Particularly high densities of fish had similar effects to nutrient enrichment on the biomass of filamentous macroalgae. This may indicate that fish density reduced the grazing activity of herbivores through non-lethal effects. Such traitmediated indirect interactions (TMIIs) are facilitated, for example, by predator cues or chemicals from crushed conspecifics (Behrens Yamada et al. 1998, van Buskirk \& Arioli 2002) and have the potential to induce cascading effects (Werner \& Peacor 2003, Schmitz et al. 2004). TMIIs are typically changes in prey behaviour, such as a reduced activity, and depend on prey density and the concentration of predator cues (van Buskirk et al. 2011). Thus, prey indi- viduals spend less time foraging to reduce their predation risk. Therefore, high predator densities may have reduced the grazing activity through non-lethal effects in addition to consumption of herbivores.

A comparison with natural fish densities is difficult since almost no data exist. However, predators are usually very mobile and forage over much larger spatial scales than the size of the cages. Therefore, we assume that predation risk was high and that herbivores reduced their grazing activity to escape predation. We also suggest using larger cages when enclosing a fish predator to mimic more natural predator densities for trophic effects. An alternative explanation for the positive effect on algal biomass could be the increasing interference with higher predator densities, particularly in the mixed assemblages, where predator density increased to high levels due to the additive design. Strong interference likely emerged from high predator density with positive effects on herbivores (risk reduction, Sih et al. 1998).

Furthermore, high densities of fish also enrich the environment through nutrient excretion (Vanni 2002, Zimmer et al. 2006). We would assume an intermediate algal growth at medium fish densities, if nutrient excretion by fish substantially influenced algal growth. However, algal biomass at medium fish densities was similar to the low fish densities. Therefore, nutrient enrichment through high fish densities probably played only a minor role in the strongly enhanced algal growth.

This experiment tested food web effects of 3 fish predator species in isolation and in a multiple predator assemblage at 3 different levels of predator density. The lowest and highest fish densities were 3 and 9 perch and roach as well as 23 and 69 stickleback per $\mathrm{m}^{-3}$, respectively. The predator manipulations were combined with nutrient enrichment in half of the assemblages to separate cascading top-down effects of predators from the effects of systems productivity on producers. However, there was no full replication for all treatment combinations (subsamples replicated each cage). Therefore, 3-way interactions were excluded from the statistical models, and the interactive effects of the nutrient treatment with one of the fish treatments have to be treated with caution (only Theodoxus biomass was affected by the combination of fish and nutrient, see Table 1). However, the treatment combination of fish composition and density were replicated twice, which was assumed to be sufficient considering the effort for such an experiment.

Ecosystems all over the world are affected by multiple anthropogenic stressors that can interact in non- 
additive ways (Crain et al. 2008). Functional extinctions of species in food webs are biased towards higher trophic levels (Byrnes et al. 2007), emphasizing the need to understand trophic interactions starting from the predator level.

Our results show that predator identity has strong effects on the composition of the next lower trophic level, and that such identity effects are altered in an assemblage of multiple predators depending on the interference among the predators. Prey switching occurred likely as a means of escaping interference. Predator density had only weak effects overall on herbivore biomass. However, predator density had positive effects on algal growth (similar to the effects of nutrient enrichment) without the associated changes in herbivores. This is indicative of either strong non-lethal effects on herbivores, for instance reduced grazing activities, or strong interference among the predators, which reduced predation pressure on herbivores.

Thus, predator density rather than predator composition strongly affected algal growth, probably because of non-lethal effects on herbivores and increasing predator interference, particularly in the mixed assemblages. This suggests that predator density may have stronger effects than fish composition in a food web, particularly on lower trophic levels through non-lethal effects on herbivores.

Acknowledgements. We thank several people for their assistance in the field or in the lab: S. Govella, C. van Sluis, L. Zigtermann, M. van Harten, D. van de Geer, and the staff at the Askö Laboratory. We thank S. Donadi for statistical advice. We also thank 3 anonymous reviewers for constructive comments on the earlier version of this manuscript.

\section{LITERATURE CITED}

Ådjers K, Appelberg M, Eschbaum R, Lappalainen A, Minde A, Repe ka R, Thoresson G (2006) Trends in coastal fish stocks of the Baltic Sea. Boreal Environ Res 11:13-25

Behrens Yamada S, Navarrete SA, Needham C (1998) Predation induced changes in behavior and growth rate in three populations of the intertidal snail, Littorina sitkana (Philippi). J Exp Mar Biol Ecol 220:213-226

Bruno JF, O'Connor MI (2005) Cascading effects of predator diversity and omnivory in a marine food web. Ecol Lett 8: 1048-1056

Byrnes JE, Stachowicz JJ (2009) The consequences of consumer diversity loss: different answers from different experimental designs. Ecology 90:2879-2888

Byrnes JE, Reynolds PL, Stachowicz JJ (2007) Invasions and extinctions reshape coastal marine food webs. PLoS ONE 2:e295

> Cardinale BJ, Duffy JE, Gonzalez A, Hooper DU and others (2012) Biodiversity loss and its impact on humanity. Nature 486:59-67
Crain CM, Kroeker K, Halpern BS (2008) Interactive and cumulative effects of multiple human stressors in marine systems. Ecol Lett 11:1304-1315

$>$ Crowder LB, Cooper WE (1982) Habitat structural complexity and the interaction between bluegills and their prey. Ecology 63:1802-1813

Douglass JG, Duffy JE, Bruno JF (2008) Herbivore and predator diversity interactively affect ecosystem properties in an experimental marine community. Ecol Lett 11:598-608

$>$ Eklöv P, Persson L (1995) Species-specific antipredator capacities and prey refuges: interactions between piscivorous perch (Perca fluviatilis) and juvenile perch and roach (Rutilus rutilus). Behav Ecol Sociobiol 37:169-178

- Eriksson BK, Ljunggren L, Sandström A, Johansson G and others (2009) Declines in predatory fish promote bloomforming macroalgae. Ecol Appl 19:1975-1988

> Eriksson BK, Sieben K, Eklöf J, Ljunggren L, Olsson J, Casini M, Bergström U (2011) Effects of altered offshore food webs on coastal ecosystems emphasizes the need for cross-ecosystem management. Ambio 40:786-797

Griffen BD (2006) Detecting emergent effects of multiple predator species. Oecologia 148:702-709

> Griffen BD, Williamson T (2008) Influence of predator density on nonindependent effects of multiple predator species. Oecologia 155:151-159

Griffin JN, de la Haye KL, Hawkins SJ, Thompson RC, Jenkins SR (2008) Predator diversity and ecosystem functioning: density modifies the effect of resource partitioning. Ecology 89:298-305

Gustafsson BG, Schenk F, Blenckner T, Eilola K and others (2012) Reconstructing the development of Baltic Sea eutrophication 1850-2006. Ambio 41:534-548

HELCOM (2006) Changing communities of Baltic coastal fish. Executive summary: assessment of coastal fish in the Baltic Sea. Baltic Sea Environ Proc No 103 B, Helsinki Commission, Baltic Marine Environment Protection Commission, Helsinki

> Ibrahim AA, Huntingford FA (1989) Laboratory and field studies on diet choice in three-spined sticklebacks, Gasterosteus aculeatus L., in relation to profitability and visual features of prey. J Fish Biol 34:245-257

> Kahl U, Radke RJ (2006) Habitat and food resource use of perch and roach in a deep mesotrophic reservoir: Enough space to avoid competition? Ecol Freshw Fish 15:48-56

$>$ Korpinen S, Jormalainen V, Ikonen J (2008) Selective consumption and facilitation by mesograzers in adult and colonizing macroalgal assemblages. Mar Biol 154:787-794

Kuhn M, Weston S, Wing J, Forester J (2011) contrast: a collection of contrast methods. $R$ package version 0.17

> Lappalainen A, Kangas P (1975) Littoral benthos of the Northern Baltic Sea. II. Interrelationships of wet, dry and ash-free dry weights of macrofauna in the Tvärminne area. Int Rev Gesamten Hydrobiol Hydrograph 60:297-312

Lappalainen A, Rask M, Koponen H, Vesala S (2001) Relative abundance, diet and growth of perch (Perca fluviatilis) and roach (Rutilus rutilus) at Tvärminne, northern Baltic Sea, in 1975 and 1997: Responses to eutrophication? Boreal Environ Res 6:107-118

Ljunggren L, Sandström A, Bergström U, Mattila J and others (2010) Recruitment failure of coastal predatory fish in the Baltic Sea coincident with an offshore ecosystem regime shift. ICES J Mar Sci 67:1587-1595

Lotze HK, Lenihan HS, Bourque BJ, Bradbury RH and others (2006) Depletion, degradation, and recovery potential of estuaries and coastal seas. Science 312:1806-1809 
Mack RN, Simberloff D, Lonsdale WM, Evans H, Clout M, Bazzaz FA (2000) Biotic invasions: causes, epidemiology, global consequences, and control. Ecol Appl 10:689-710

MacNeil C, Dick JT, Elwood RW (1997) The trophic ecology of freshwater Gammarus spp. (Crustacea: Amphipoda): problems and perspectives concerning the functional feeding group concept. Biol Rev Camb Philos Soc 72: 349-364

Naeem S, Duffy JE, Zavaleta E (2012) The functions of biological diversity in an age of extinction. Science 336: 1401-1406

Neumann D (1961) Ernährungsbiologie einer rhipidoglossen Kiemenschnecke. Hydrobiologia 17:133-151

Nilsson J, Andersson J, Karås P, Sandström O (2004) Recruitment failure and decreasing catches of perch (Perca fluviatilis L.) and pike (Esox lucius L.) in the coastal waters of southeast Sweden. Boreal Environ Res 9:295-306

O'Connor MI, Bruno JF (2009) Predator richness has no effect in a diverse marine food web. J Anim Ecol 78: $732-740$

O'Gorman EJ, Enright RA, Emmerson MC (2008) Predator diversity enhances secondary production and decreases the likelihood of trophic cascades. Oecologia 158:557-567

Orav-Kotta H, Kotta J (2003) Seasonal variations in the grazing of Gammarus oceanicus, Idotea baltica, and Palaemon adspersus on benthic macroalgae. Proc Estonian Acad Sci Biol Ecol 52:141-148

> Pace ML, Cole JJ, Carpenter SR, Kitchell JF (1999) Trophic cascades revealed in diverse ecosystems. Trends Ecol Evol 14:483-488

Persson L (1987) Effects of habitat and season on competitive interactions between roach (Rutilus rutilus) and perch (Perca fluviatilis). Oecologia 73:170-177

Pimm SL, Russell GJ, Gittleman JL, Brooks TM (1995) The future of biodiversity. Science 269:347-350

Pinheiro J, Bates D, DebRoy S, Sarkar D, R Development Core Team (2013) nlme: linear and nonlinear mixed effects models. R package version 3.1-108

Polis GA, Holt RD (1992) Intraguild predation: the dynamics of complex trophic interactions. Trends Ecol Evol 7: 151-154

Polis GA, Myers CA, Holt RD (1989) The ecology and evolution of intraguild predation: potential competitors that eat each other. Annu Rev Ecol Syst 20:297-330

R Development Core Team (2012) A language and environment for statistical computing. R Foundation for Statistical Computing, Vienna, available at www.R-project.org

Råberg S, Kautsky L (2007) Consumers affect prey biomass and diversity through resource partitioning. Ecology 88: 2468-2473

Editorial responsibility: Romuald Lipcius, Gloucester Point, Virginia, USA
Salemaa H (1987) Herbivory and microhabitat preferences of Idotea spp. (Isopoda) in the northern Baltic Sea. Ophelia 27:1-15

Schmitz OJ, Krivan V, Ovadia O (2004) Trophic cascades: the primacy of trait-mediated indirect interactions. Ecol Lett 7:153-163

> Sieben K, Rippen A, Eriksson B (2011) Cascading effects from predator removal depend on resource availability in a benthic food web. Mar Biol 158:391-400

> Sih A, Englund G, Wooster D (1998) Emergent impacts of multiple predators on prey. Trends Ecol Evol 13: 350-355

> Snaydon RW (1991) Replacement or additive designs for competition studies? J Appl Ecol 28:930-946

- Soluk DA (1993) Multiple predator effects: predicting combined functional response of stream fish and invertebrate predators. Ecology 74:219-225

Sommer U (1997) Selectivity of Idothea chelipes (Crustacea: Isopoda) grazing on benthic microalgae. Limnol Oceanogr 42:1622-1628

Stachowicz JJ, Bruno JF, Duffy JE (2007) Understanding the effects of marine biodiversity on communities and ecosystems. Annu Rev Ecol Evol Syst 38:739-766

van Buskirk J, Arioli M (2002) Dosage response of an induced defense: How sensitive are tadpoles to predation risk? Ecology 83:1580-1585

> van Buskirk J, Ferrari M, Kueng D, Näpflin K, Ritter N (2011) Prey risk assessment depends on conspecific density. Oikos 120:1235-1239

> Vance-Chalcraft HD, Soluk DA, Ozburn N (2004) Is prey predation risk influenced more by increasing predator density or predator species richness in stream enclosures? Oecologia 139:117-122

Vanni MJ (2002) Nutrient cycling by animals in freshwater ecosystems. Annu Rev Ecol Syst 33:341-370

Werner EE, Peacor SD (2003) A review of trait-mediated indirect interactions in ecological communities. Ecology 84:1083-1100

Werner EE, Mittelbach GG, Hall DJ, Gilliam JF (1983) Experimental tests of optimal habitat use in fish: the role of relative habitat profitability. Ecology 64:1525-1539

Worm B, Barbier EB, Beaumont N, Duffy JE and others (2006) Impacts of biodiversity loss on ocean ecosystem services. Science 314:787-790

> Zimmer KD, Herwig BR, Laurich LM (2006) Nutrient excretion by fish in wetland ecosystems and its potential to support algal production. Limnol Oceanogr 51:197-207

Zuur AF, Ieno EN, Walker NJ, Saveliev AA, Smith GM (2009) Mixed effect models and extensions in ecology with R. Springer, Berlin

Submitted: May 3, 2013; Accepted: October 24, 2013

Proofs received from author(s): December 16, 2013 